\title{
STEM - NASA Undergraduate Research in a Minority - Serving Community College
}

Nieves Angulo, Alexander Vaninsky

Mathematics Department, Hostos Community College of The City University of New York 500 Grand Concourse, Bronx, NY 10451 USA nangulo@hostos.cuny.edu

Mathematics Department, Hostos Community College of The City University of New York 500 Grand Concourse, Bronx, NY 10451 USA

\section{ABSTRACT}

avaninsky@hostos.cuny.edu

The paper analyses undergraduate research in a minority - serving community college and provides an example of a specially developed mathematics program aimed at academic preparation leading to the increase of the efficiency of the following field work at the NASA premises.

\section{Indexing terms/Keywords}

Engineering education, NASA, Community colleges, Minority serving institutions.

\section{Academic Discipline And Sub-Disciplines}

Engineering Education; Mathematics Education; Minority Serving Institutions;

\section{SUBJECT CLASSIFICATION}

Library of Congress ClassificationLB2300-2430 Higher education

\section{TYPE (METHOD/APPROACH)}

Quasi-Experimental

\section{Council for Innovative Research}

Vol 4, No 2

jssreditor.cir@gmail.com

www.cirworld.com 


\section{INTRODUCTION}

Undergraduate research is an important element of the STEM - major students' preparation. It comprises the investigation of relevant problems, field work, preparation of a research report, and presenting results at scientific conferences. As a result, undergraduate students specializing in Science, Technology, Mathematics, or Engineering (STEM) become better prepared for both graduate study and practical work, whatever way they choose to continue. Different aspects of the STEM - related undergraduate research are considered in the literature and attract attention of the government, Olson and Riordan [15].

In the literature sources, Campisi and Finn [4] discussed the experience of incorporation of first-year sports medicine majors into the research projects in the framework of the Research Methods course. Students were working in small research groups aimed at the identification of a research question, generating hypotheses to be tested, designing and implementation of an experiment, analyzing the obtained results, and presenting their findings. It was found that the participants were able to grasp the relevant research methodology, theories and principles, to acquire competency in research methodology, techniques, to develop interpersonal and professional skills, and to improve their attitude regarding science and the research process.

Eagan et al. [5] investigated the factors affecting the involvement of undergraduates in the research projects. They found that faculty who work in the life sciences and those who receive government funding for their research are more likely to involve undergraduates in their research projects. Also, the faculty at Historically Black colleges are significantly more likely to involve undergraduate students in research. The authors further discuss the advancing undergraduate research opportunities.

Kim et al. [14] described promising practices in undergraduate research experiences that promote women's long-term interest in computer science and engineering. This article explores whether and how undergraduate research experiences serve to promote gender equity and identify specific mechanisms that are effective in supporting women and encouraging them to persist in computer science and engineering fields. Gresty and Edwards-Jones [10] investigated an impact of publishing the undergraduate student research in a science e-journal. The students were involved in the research in a variety of ways: honors projects, lab work and field work. Their research showed that the students wanted to be more actively involved in the research process and an opportunity to publish increased their interest in the research.

Edwards et al. [6] described a year long structured program that guided graduate student mentors and their undergraduate mentees through the research process. Fechheimer et al. [8] Investigated the impact of student participation in the undergraduate research on credit-hour generation and grade point average. Their results show that participation in a research project for more than one is correlated with an increase in the grade point average (GPA). limoto and Frederick [13] described the implementation of a developmental process to help students design and execute their own research projects in a two-course sequence. Students started with reading scientific literature to a research question for a project proposal. Then the students executed the project in the integrated laboratory, where they troubleshoot experiments, collected and interpreted data, and drew conclusions. The authors report positive results of their strategy.

Heidelet et al. [12] described the results of a five-year Science\& Technology Entry Program (STEP) funded by the National Science Foundation (NSF) aimed to increase the number of homegrown STEM graduates. They have found that the overall project has been successful, and the numbers of degrees granted has increased. Some strategies have worked better than the others. Among the successful strategies are close collaboration between the two institutions, support for walk-in tutoring, early undergraduate research, bridge scholarships, and adult learner scholarships. On the other hand, targeting incoming freshmen as recipients of scholarships was expensive and relatively ineffective at increasing the number of STEM graduates.

Ovink et al. [17] mentioned that the minority students continue to be underrepresented among those who seek graduate and professional degrees in the sciences. These students experience psychological - social barriers and lack of institutional support. Based on a case study of a university - sponsored intervention program for minority science majors that addressed both academics and socialization into the academic community and networking, the authors suggest that concerted efforts directed toward expanding "habits" and thereby augmenting cultural and social capital may have positive effects for the underrepresented minority college students' academic and career prospects.

Wesley et al. [28] estimated the results of more than 40 yearlong national efforts to promote diversity among the scientific research community. They report the results from a longitudinal study of students supported by a National Institutes of Health-funded minority training program. Their research shows that students supported by the Research Initiative for Scientific Excellence were more likely to persist in their intentions to pursue a scientific research career. It was also shown that namely undergraduate research experience, but not having a mentor, affects student persistence in science.

Espinosa [7] examined the effect of pre-college characteristics, college experiences, and institutional setting on the persistence of undergraduate women of color in the STEM majors and investigates how this pathway might differ for women of color in comparison to their white peers. Guinn [11] furnishes the results of the Environmental Science Program, basing it on the scientific method and techniques that students would need for employment in environmental technician positions with local and tribal agencies. Students were requested to conduct and defend a full research project for graduation. This requirement was well received and has led to many unexpected benefits. Research and presentations were a core part of the Program and enhanced a student organization, professionalism, and critical thinking skills. The program includes: Semester Research Courses, Summer Research Experience for Undergraduates, Native 
Undergraduates Tropical Research Opportunities, and an Experimental Program to Stimulate Competitive Research's Nurturing American Tribal Undergraduate Research and Education.

Thiry and Laursen [26]-[27] investigated the sources of the current interest in the undergraduate research. They mention the scientists' preparation and concerns about replacing the current scientific workforce as principal factors. They point out the range of personal, professional, and intellectual benefits for STEM students from participating in the undergraduate research and mention that the processes of student-advisor interactions contribute is still little understood. Their research demonstrates, in particular, that out-of-class experiences fostered many intellectual, personal, and professional gains. Undergraduate research helped to shape science identities and to socialize students into the scientific profession. They assert that participation in authentic, independent work with adequate guidance is critical to student learning and development.

Adedokun and Burgess [1] addressed students' preconceptions regarding research internships and their relationships to actual experiences. They claim that these preconceptions impact the learning process and the gains that accrue to students involved in undergraduate research experiences. The obtained results show that the participants in the undergraduate research initially imagined research environments/laboratories as stern places devoid of social interactions. Interns also held preconceived traditional stereotypical views of their faculty mentors as scientists. Other preconceptions included the expectation of extensive one-on-one mentoring from faculty mentors and the preconception of research work as a team rather than independent work. The study found that students' preconceptions were mostly contradicted by their experiences in their research internships.

Reynolds and Thompson [22] stressed that the undergraduates have to learn to write like scientists. They assert that writing a thesis after participating in faculty-mentored undergraduate research is a convenient way of developing writing skills. This process requires combining writing courses with individualized mentoring. They present a hybrid model in which students have the structural support of a course and enjoy the personalized benefits of working one-on-one with faculty.

Other aspects of the undergraduate research, including the community colleges, are considered in publications of Berrett [2], Brewer and Anne [3], Feldman and Kent [9], Olson and Labov [16], Romsdahl and Hill [23], Ryser et al. [24], and Schwartz [25].

This paper, in line with the previous publications, describes an experience of running a NASA - related undergraduate research program developed and implemented in a community college that is a unit of a comprehensive city university. We describe an example of a specially developed mathematics program aimed at academic preparation leading to the increase of the efficiency of the following field work at the NASA premises.

\section{NASA PROGRAM}

The National Aeronautics and Space Administration (NASA) needs institutions of higher education aimed to improve the relevant skills of graduates at both technical and professional levels. Historically, minority students in community colleges have had very few opportunities to apply the principles they learn in the ways that are relevant to NASA needs. Furthermore, as President Obama has conveyed to the nation, there is a need to focus particularly on the restoration of America's leadership in Higher Education with special emphasis on the role played by community colleges in STEM areas. NASA has stepped forward with the development of programs for higher education aimed particularly to populations at community colleges to engage and foster everyone that could be able to advance the nation's vital goals and objectives. ASA has made it possible for community college students to engage early on in projects at their centers across the nation that has contributed to the demystification of the perception of NASA as an entity too far from this particular student body population and impossible to attain. The latter has been possible by internships where students as well as faculty from the community colleges have worked alongside NASA engineers and researchers for full summer months. Furthermore, the introduction of NASA-related materials into the community college's curricula has made students aware of NASA aims and goals and opened a window with respect to their careers and future goals. We have developed partnerships with two NASA centers, the Marshall Space Flight Center (MSFC) in Huntsville, Alabama and the Goddard Institute for Space Studies (GISS) in New York City. These two NASA centers have been collaborating with us for the past 3 years with impressive results to show. Hostos, our community college, is located in the South Bronx and is the smallest in the City University of New York (CUNY) system in New York City with 6,835 students, of which $66.8 \%$ are females, 59.1\% are Hispanic, 24.7\% are African American, $85 \%$ are eligible for Federal Financial Aid and only 9.8\% of freshmen students pass all three skills tests in Mathematics, Reading and Writing. Seeing the need in STEM areas and our reality in our students' preparation, STEM faculty developed a Dual/Joint Engineering Program with the school of engineering at the senior college. This Dual/Joint program offers a mirror image of the first two years of the engineering at the senior college with the conveniences and nurture of a community college environment. The idea was that community college students should not wait until they transfer to the senior college to engage in research or learn about STEM areas. In the Fall of 2003, Hostos CC established the first Dual/Joint program with the school of Engineering at the senior college in CUNY, first of its class. Today we offer Electrical, Mechanical, Civil and Chemical engineering programs at our institution. The enrollment in these programs has grown rapidly from less than 10 students in 2003 to over 164 students in 2014, making it one of the fastest growing programs at the college. As mentioned before, the signature feature of the engineering programs in our community college is the research experience beginning in the freshman year. This opportunity allows the students to obtain a better preparation and enhance their skills in STEM-related disciplines. In order to involve students in the research work, special awards were established and some courses were restructured to introduce the following 
objectives: (i) to make students more confident in team work and (ii) to develop skills in scientific report writing. In a posteriorly conducted survey, $73 \%$ of the students evaluated their team work experience as very helpful.

Some community college students have underestimated the level of preparation needed to accomplish the program that resulted in the low graduation rates. In our programs, the graduation rates in 6 years were in the range of $6.1 \%$ to $22.4 \%$, depending on the specialization. This problem requires special research and actions aimed at the improvement of the situation. As a positive result, it was found that the NASA-related program served as a venue: high school - community college - senior college - master's degree - for dedicated minority students who were able to complete it. Its heightened research emphasis opened up the scientific/engineering enterprise to students at a very early point in their academic careers, while maintaining focus on meeting the daily educational needs of students. It was drawn upon the urban infrastructure and metropolitan resources that have strengthened the institutional linkages and expanded the opportunities for students' research, scholarly communications, and collaboration with the sciences and engineering community at other universities, federal agencies, and technology-related businesses.

\section{ON-SITE ACADEMIC PREPARATION FOR THE FIELD WORK}

To prepare students for successful field work on the NASA site, the Mathematics, Natural Science, and English Departments work in cooperation during the two semesters preceding the field trip. Thus, the Natural Science Department makes them acquainted with the engineering, bio - science, and technological problems typical for the NASA activities. The English Department teaches how to maintain a research journal, to write a research report and executive summary, and to prepare a presentation. The Mathematics Department adjusted the post - calculus courses to include topics needed for better understanding of the NASA research and engineering accomplishments.

This section provides an example of the adjustments made to the Differential Equations course by the Mathematics Department. The main objectives of the course adjustment were:

To teach formalization of the problems stated as the subject - related ones;

To provide examples of deriving differential equations that describe the problem;

To present computer - based tools of solutions of the differential equations that cannot be solved analytically;

To encourage students to investigate the obtained solutions, to interpret them in terms of the subject - related problem, and to make sound practical decisions and conclusions.

One of the adjusted-course requirements was the preparation and presentation of a group project. As a means of encouragement, this project gave students extra credit toward the final grade for the course. An example of one of the research project is investigation of air quality control and dynamics at the International Space Station (ISS). Theoretical sessions were organized for the Engineering majors in the framework of a course in Differential Equations. We started with reading and discussion of a series of articles related to the problem: Perry [18]-[20] and Perry and Peterson [21]. We follow these publications in this section. It was mentioned in the literature sources that a variety of factors affect the quality of cabin air. The main factors are equipment offgasing and crew metabolic loads. Among other factors are leaks from the system equipment and payload facilities, operational status of atmospheric scrubbing systems, maintaining and installation of new equipment and modules, and the vehicle's operational configuration. Different chemical contaminants influence both crew health and equipment performance.limits for most volatile cleaning solvents. Using them in large qualities during the ground processing or in-flight operational phases of a crewed spacecraft can lead to significant challenges to the water processing systems. The problem needs mathematical modeling to understand the relationships between the cabin atmospheric quality and the loading of humidity condensate. A spacecraft cabin may be considered as a "tight building". Its atmosphere is recycled with just very small quantities of fresh makeup gases aimed to balance the overboard leakage. As a result, particular attention should be given to the control of airborne contamination process at all stages of the project design. Airborne contaminants include volatile chemicals, particulate matter, and microbes. They directly impact the crew's well-being and performance. Another issue is the choice of construction materials that must meet a host of design requirements, including low rates of offgasing and resistance to the microbial growth.

Students were asked to follow Perry (2005) in the development of a mathematical model of formaldehyde concentration dynamics in the cabin of the International Space Station (ISS). The Station comprised two blocks: the United State's and the Russian's, correspondingly. Reports from theon - orbit segments indicated the increase in the formaldehyde concentration in the US - segment while remaining relatively stable in the Russian one. At one moment, the concentration peak even exceeded the maximum allowable level. Another observation was the unusual $\mathrm{CO} 2$ gradient between the two blocks. The improvements based, in particular, on the mathematical modeling, revealed that the formaldehyde concentration in the US - block is strongly dependent on maintaining normal ventilation between the blocks and the performance of the active contamination control system in the Russian block. Students have studied a system of differential equations describing the process. They were asked to follow the logic of the derivation of the differential equations and to explain the meaning of each of the terms. The research project comprised investigation of the problem, maintaining a differential equation, learning Maple software and writing a program for its solution, presenting the results in analytical and graphic forms, making a presentation aimed at their preliminary discussion. In addition to the group projects, students were encouraged to attempt to write a research paper on the topic. During the fieldwork summer session at one of the NASA Centers, further discussion and elaboration of the obtained results were conducted. 


\section{CONCLUSION}

The paper presents an analysis and an example of the undergraduate research in a minority - serving community college that is a part of a comprehensive city university. We discuss administrative issues, on-site preparation, and provisions for a field research work at the NASA Centers in the summer period. In the period of $2011-2013$, twelve students were involved in the NASA program. All of them continue their study beyond the Associate's Degree, pursuing STEM-related Bachelor's or Master's Degrees. Two students were invited for the internship at the Brookhaven National Laboratory (BNL), Upton, NY, and one was assigned a NASA Ambassador Student. Though statistical data on the life-changing consequences are not fully clear at this time, it may be stated that participation in the NASA undergraduate research projects leads to personal advances, encourages continued academic study, and provides better job opportunities - all of the issues especially important for the underrepresented minority student body.

\section{REFERENCES}

[1] Adedokun, O.and Burgess W. 2011.Uncovering Students' Preconceptions of Undergraduate Research Experiences, J. of STEM Education: Innovations and Research, 12(5-6),12-22.

[2] Berrett, D. 2012. With NSF Support, Research Moves into Science Labs of 2-Year Colleges, Chronicle of Higher Education, January.2012.

[3] Brewer, G. and Anne, D. 2012. Undergraduate research projects: Practice and perceptions, Psychology Learning \& Teaching, 11(2), 208-217.

[4] Campisi, J. and Finn, K. 2011. Does Active Learning Improve Students' Knowledge of and Attitudes toward Research Methods?, J. of College Science Teaching, 40(4), 38-45.

[5] Eagan, M., Sharkness, J., Hurtado, S.,Mosqueda, C., and Chang, M. 2011. Engaging Undergraduates in Science Research: Not Just about Faculty Willingness, Research in Higher Education, 52(2), 151-177.

[6] Edwards, T., Smith, B., Watts, D., Germain-Aubrey, C., Roark, A., Bybee, S., Cox, C., Hamlin, H., and Guillette, L. 2011. Group-Advantaged Training of Research (GATOR): A Metamorphosis of Mentorship, BioScience, 61(4), 301311.

[7] Espinosa, L. 2011. Pipelines and Pathways: Women of Color in Undergraduate STEM Majors and the College Experiences That Contribute to Persistence, Harvard Educational Review, 81(2), 209-241.

[8] Fechheimer, M., Webber, K., and Kleiber, P. 2011. How Well Do Undergraduate Research Programs Promote Engagement and Success of Students?, CBE - Life Sciences Education, 10(2), 156-163.

[9] Feldman, A. and Kent, A. 2013. Becoming researchers: The participation of undergraduate and graduate students in scientific research groups, Science Education, 97(2), 218-243.

[10] Gresty, K., and Edwards-Jones, A. 2012. Experiencing Research-Informed Teaching from the Student Perspective: Insights from Developing an Undergraduate E-Journal, British J. of Educational Technology, 20, 43(1), 153-162

[11] Guinn,J. 2011. Retention through Research: Sitting Bull College Builds STEM Program around Research Experiences, Tribal College J. of American Indian Higher Education, 22(4).

[12] Heidel, J., Ali, H., Corbett, B., Liu, J., Morrison, B., O'Connor, M., Richter-Egger, D. and Ryan, C. 2011. Increasing the Number of Homegrown STEM Majors: What Works and What Doesn't, Science Educator, 20(1), 49-54.

[13] limoto, D. and Frederick, K. 2011. Incorporating Student-Designed Research Projects in the Chemistry Curriculum, J. of Chemical Education, 88(8), 1069-1073.

[14] Kim, K., Fann, A. and Misa-Escalante,K. 2011. Engaging Women in Computer Science and Engineering: Promising Practices for Promoting Gender Equity in Undergraduate Research Experiences, ACM Transactions on Computing Education, 11(2), Article \#8.

[15] Olson, S. and Riordan, D. 2012. Engage to Excel: Producing One Million Additional College Graduates with Degrees in Science, Technology, Engineering, and Mathematics, Report to the President ED541511, Executive Office of the President.

[16] Olson, S. and Labov, J. 2012. Community Colleges in the Evolving STEM Education Landscape: Summary of a Summit, National Academies Press.

[17] Ovink, S. and Veazey, B. 2011. More than Getting Us through: A Case Study in Cultural Capital Enrichment of Underrepresented Minority Undergraduates, Research in Higher Education, 52(4), 370-394.

[18] Perry, J. 2005. Formaldehyde Concentration Dynamics of the International Space station Cabin Atmosphere. National Aeronautics and space Administration, Marshall Space Flight Center.

[19] Perry, J. 2001. Predictive Technique for Spacecraft Cabin Air Quality Control, National Aeronautics and space Administration. Marshall Space Flight Center.

[20] Perry, J. 2002. The Interaction of Spacecraft Cabin Atmospheric Quality and Water Processing System Processing Performance, National Aeronautics and space Administration. Marshall Space Flight Center.

[21] Perry, J. and Peterson, B.2003. Cabin Air Quality Dynamics on Board the International Space Station, National Aeronautics and Space Administration. Marshall Space Flight Center. 
[22] Reynolds, J. and Thompson, R. 2011. Want to Improve Undergraduate Thesis Writing? Engage Students and Their Faculty Readers in Scientific Peer Review, CBE - Life Sciences Education, 10(2), 209-215.

[23] Romsdahl, R. and Hill, M. 2012. Applying the learning community model to graduate education: Linking research and teaching between core courses, Teaching in Higher Education, 1(6), 722-734.

[24] Ryser, L., Markey, S. and Halseth, G. 2013. Developing the next generation of community-based researchers: Tips for undergraduate students, J.of Geography in Higher Education, 37(1), 11-27.

[25] Schwartz, J. 2012. Faculty as undergraduate research mentors for students of color: Taking into account the costs, Science Education, 96(3), 527-542.

[26] Thiry, H. and Laursen, S. 2011. The Role of Student-Advisor Interactions in Apprenticing Undergraduate Researchers into a Scientific Community of Practice, J. of Science Education and Technology, 20(6), 771-784.

[27] Thiry, H., Laursen, S. and Hunter, A. 2011. What Experiences Help Students Become Scientists? A Comparative Study of Research and Other Sources of Personal and Professional Gains for STEM Undergraduates, J. of Higher Education, 82(4), 357-388.

[28] Wesley, S., Hernandez, P., Woodcock, A., Estrada, M., Chance, R., Aguilar, M. and Serpe, R. 2011. Patching the Pipeline: Reducing Educational Disparities in the Sciences through Minority Training Programs, Educational Evaluation and Policy Analysis, 33(1), 95-114.

\section{Author' biography with Photo}

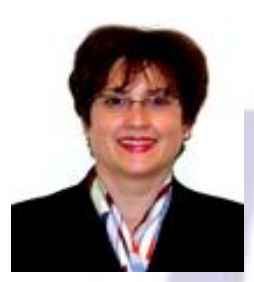

Dr. Nieves Angulo - Mathematics Dept. Hostos Community College, Bronx, New York - is an Associate Professor in the Mathematics Department and the Coordinator of the Engineering Program in the department. She has a pure B.A. and M.A. in Mathematics from Hunter College of CUNY, and an M.S and Ed.D.in Mathematics Education from Columbia University. Dr. Angulo has worked since 2002 in the development and implementation of the Dual/Joint Engineering Programs at Hostos. Having served as Deputy Chair of the Mathematics Department, Director of the Honors Program, Liaison, Coordinator and Director for the Engineering Programs at the college level, she brings a wealth of experience in managing and leading integrative educational initiatives in higher education. Dr. Angulo has been very active in externally funded initiatives dedicated to improving proficiency in STEM education including collaborative projects with NSF, DoE and NASA.

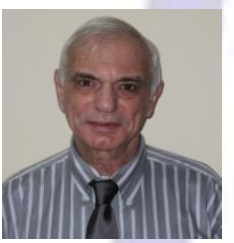

Dr. Alexander Vaninsky is currently a Professor of Mathematics at Hostos Community College of the City University of New York. He received his master's degree in electrical engineering from the Moscow Power Engineering Institute, in mathematics - from Moscow State University, and Ph.D. and D. Sc. Degrees in mathematical economics - from Moscow Finance University. Author and co-author of five monographs and over 30 articles. Recipient of different grants and awards; among them - Stephen J. Shaw Award for Most Outstanding Paper (Irwin Publishing, USA) and Award for Outstanding Paper in Channels, Retail \& Services (Southern Marketing Association of the USA). Teaches courses in Mathematics and Economics.Served as a Member of the Board of Directors and an advisor to government and private companies.Included in the Who's Who in America and Who's Who in the World. His current research focuses on the development and applications of new methods of environmental analysis including structured input - output models and data envelopment analysis with a perfect object. 